\title{
Impedance spectroscopy as a tool to study modifications in the microstructure of concrete in ionic migration experiments
}

\author{
G. de Vera, M. A. Climent \& I. Sánchez \\ Departament d'Enginyeria de la Construcció, \\ Obres Publiques i Infraestructura Urbana, Universitat d'Alacant, Spain
}

\begin{abstract}
The study of the penetration of chloride ions in concrete structures is of great interest, because of the pernicious effects that these ions have on the corrosion of steel reinforcements. Accelerated methods have been developed to obtain the diffusion coefficient of chlorides through cement-based materials. One of these methods allows the calculation of both steady and non-steady state diffusion coefficients using a very simple conductivity measurement [1]. The presence of an electric field causes modifications in the microstructure of cement-based materials, and also an acid attack can be produced on the material if the porosity is high enough [2]. As has already been proved, impedance spectroscopy is a powerful technique to study the microstructure of cement-based materials [3]. This technique is used to characterize during the experiment the modifications that are produced in the microstructure of concrete samples during the forced migration tests. The results obtained using impedance spectroscopy have been compared with the results obtained with the mercury intrusion porosimetry, and a very good agreement has been observed.
\end{abstract}

Keywords: impedance spectroscopy, ionic migration, diffusion, chloride, microstructure.

\section{Introduction}

Chloride ions are responsible of many of the corrosion problems of steel embedded in reinforced or prestressed concrete. These corrosion phenomena lead frequently to early deterioration and eventually to risky situations for the stability of structures. In any case, the economical costs inherent to reparation works are 
considerable. The most frequent cause of the presence of $\mathrm{Cl}^{-}$in concrete is its ingress from environment and through the pore paths of concrete. Big efforts have been made to design test methods of chloride ingress into concrete [4-8]. Most methods intend to determine $\mathrm{Cl}^{-}$transport parameters, mainly the diffusion coefficient. These parameters can be used, in conjunction with transport models, for service life estimations of new or existing structures [8]. Pure diffusion tests are time consuming and involve big experimental effort for chemical analysis of $\mathrm{Cl}^{-}$content of many samples. This lead early to the proposal of forced migration tests, based on the application of electrical fields, to speed up the transport of ions through concrete specimens [6]. Both steady-state and non steady-state ionic diffusion coefficients can be derived from migration experiments. Several researches have shown that ionic migration through concrete causes microstructural variations [9]. These modifications have been studied mainly by mercury intrusion porosimetry (MIP) and by scanning electron microscopy (SEM) analysis, which are destructive techniques. The technique used in the present work to determine modifications in concrete microstructure has been impedance spectroscopy (IS), which is a non-destructive one. A recently published work [10] shows the influence of migration on the impedance spectra. However, this study does not intend to study microstructural changes, but proposes a new theoretical study on the influence of the AC electric field on the ionic transfer. The simplicity of impedance measurements, and the possibility of measuring in situ, whenever it is considered necessary, suggests that IS technique is really useful to study the modifications that can be introduced in concrete microstructure by means of forced migration. The main interest of the present paper is to establish the possibility of using impedance spectroscopy to measure the modifications in microstructure in real time and without perturbing the migration experimental conditions.

\section{Experimental setup}

Concrete samples were prepared using CEM II A-L 42.5R. The water/cement ratio used was 0.5 . The dosage used for concrete preparation is shown in Table 1 . The mixture was cast in cylindrical moulds $10 \mathrm{~cm}$ in diameter, and $10 \mathrm{~cm}$ high. Samples were kept at $100 \%$ RH during the hardening time, until starting the experiment. The samples were cut into slices of $1 \mathrm{~cm}$ thick. These slices were placed in the cells designed for the forced migration tests.

Table 1: $\quad$ Composition of concrete.

\begin{tabular}{|l|r|}
\hline \multicolumn{1}{|c|}{ Component } & Dosage $\left(\mathrm{kg} / \mathrm{m}^{3}\right)$ \\
\hline Cement II A-L 42.5R & 350 \\
Coarse aggregate 6-12mm & 714 \\
Coarse aggregate 4-6mm & 489.5 \\
Sand & 662.75 \\
Water & 175 \\
Plasticizer & 1.40 \\
\hline
\end{tabular}




\subsection{Forced migration tests}

The forced migration experiments have been performed following essentially an experimental procedure described in [6], which is based on monitoring the conductivity of the anolyte. This procedure allows one to obtain both the steadystate and the non steady-state diffusion coefficients. The concrete samples were preconditioned previously to the migration tests, following a standardized water saturation procedure [11]. The cell consists of two electrolyte compartments separated by the sample. Two stainless steel rods are used as electrodes in order to apply the driving electrical field. Catholyte and anolyte chambers are filled with a $1 \mathrm{M} \mathrm{NaCl}$ solution and with distilled water, respectively. A voltage of $12 \mathrm{~V}$ is applied, and the effective potential drop between both sides of the concrete disc is measured periodically by means of two saturated calomel reference electrodes (SCE). Conductivity measurements were performed with a Crison GLP31 conductimeter (Barcelona, Spain), with automatic compensation of the readings to $25^{\circ} \mathrm{C}$ standard temperature. Temperature data of the electrolytes were also recorded, and in some cases $\mathrm{pH}$ in both chambers was also measured.

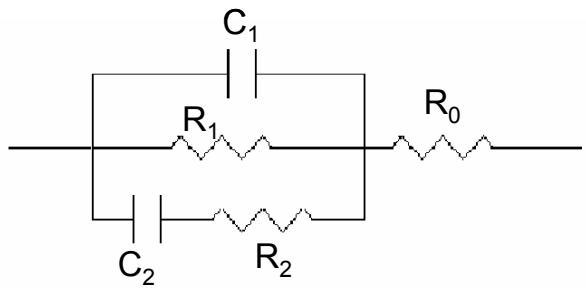

Figure 1: Equivalent circuit used for the interpretation of the impedance spectroscopy measurements in the high frequency region.

\subsection{Impedance spectroscopy measurements}

The impedance spectra of the system solutions-concrete disk were obtained using an AGILENT 4292A impedance analyser. This equipment permits the measurement in the frequency range from $40 \mathrm{~Hz}$ to $110 \mathrm{MHz}$. The impedance analyzer allows measurements in a capacitance range from $10^{-14} \mathrm{~F}$ to $0.1 \mathrm{~F}$ with a precision of $10^{-15} \mathrm{~F}$. A two-electrode configuration (flexible graphite circular electrodes with $6.5 \mathrm{~cm} \varnothing$ ) was employed to perform the measurements. Impedance spectra were measured in the frequency range from $100 \mathrm{MHz}$ to 100 $\mathrm{Hz}$, because this is the range were dielectrical properties appear [12]. The obtained impedance spectra were validated using the Kramers-Kronig (K-K) relations, to ensure causality, linearity and stability of the measurements made, with satisfactory results. Measured data were fitted to an equivalent circuit to obtain the parameters of interest in the system. The circuit used in this work, shown in Figure 1, has already been proposed [13, 14]. The circuit was originally proposed for cement paste but it has been shown to be effective to fit the impedance spectra obtained for cement mortar, just including the aggregates into the solid phase [13]. The fitting of the measured data to the model proposed is made using a simplex optimization method which is described elsewhere [15]. 


\subsection{Mercury intrusion porosimetry}

In order to validate the microstructural modifications detected with the impedance spectroscopy measurements, a classical and well-known technique, such as mercury intrusion porosimetry was used. The pore structure of different samples, at different times of exposure to chloride migration was determined using this technique. Samples were vacuum dried for 48 hours and then kept in oven at $50^{\circ} \mathrm{C}$. This procedure assures that no structural water is evaporated. With this preparation, the chosen value for the contact angle was of $130^{\circ}$. To ensure that samples used for this measurements were representative they were cut off with irregular and random shapes. The porosimeter employed was an AUTOPORE IV 9500 from Micromeritics. This porosimeter allows pore diameter determination in the range from $5 \mathrm{~nm}$ to $0.9 \mathrm{~mm}$. It has to be considered, that as reported by Diamond [16], only the dimensions of the pore superficial structure can be detected by MIP, and the irregularities in pore shape cannot be determined. Nevertheless, information on the possible tortuosity of pore network can be obtained from the mercury retained in the sample after the end of the experiment. The analysis of the curve plotting the logarithmic differential intrusion volume vs. pore size, or applied pressure, shows the size ranges where pores appear. It is possible to determine the number of pore families that exist in the sample, and the contribution of each one to the total porosity of the sample.

\section{Results and discussion}

\subsection{Forced migration results}

After the beginning of the experiment the values of conductivity and temperature on both cathodic and anodic sides, and the potential drop between both sides of the sample were measured. As it has been shown in [6] the conductivity in the anodic side is proportional to the chloride content in this solution. Results are depicted in Figure 2. It can be seen for anolyte that conductivity does not show a significant growth during the first 42 hours (time lag), and then it increases linearly. During the initial hours chlorides penetrate concrete, until the sample is chloride saturated. After this saturation time chloride concentration increases in the anolyte. This situation allows the calculation of diffusion coefficients both in stationary and non stationary states. Conductivity increases in both sides of concrete as migration proceeds. The increase in the conductivity of the cathodic side is due to the migration of cations from concrete, and also due to the products of cathodic electrode reactions, where $\mathrm{OH}^{-}$is produced. These ions have a much greater mobility than the $\mathrm{Cl}^{-}$, and make the catholyte more conductive. This last effect can be seen in figure 2(D), where $\mathrm{pH}$ in both catholyte and anolyte chambers has been recorded during the migration test. The main electrodic reaction on the cathode is water reduction and hence $\mathrm{OH}^{-}$formation, which explains $\mathrm{pH}$ and conductivity increase of catholyte. 

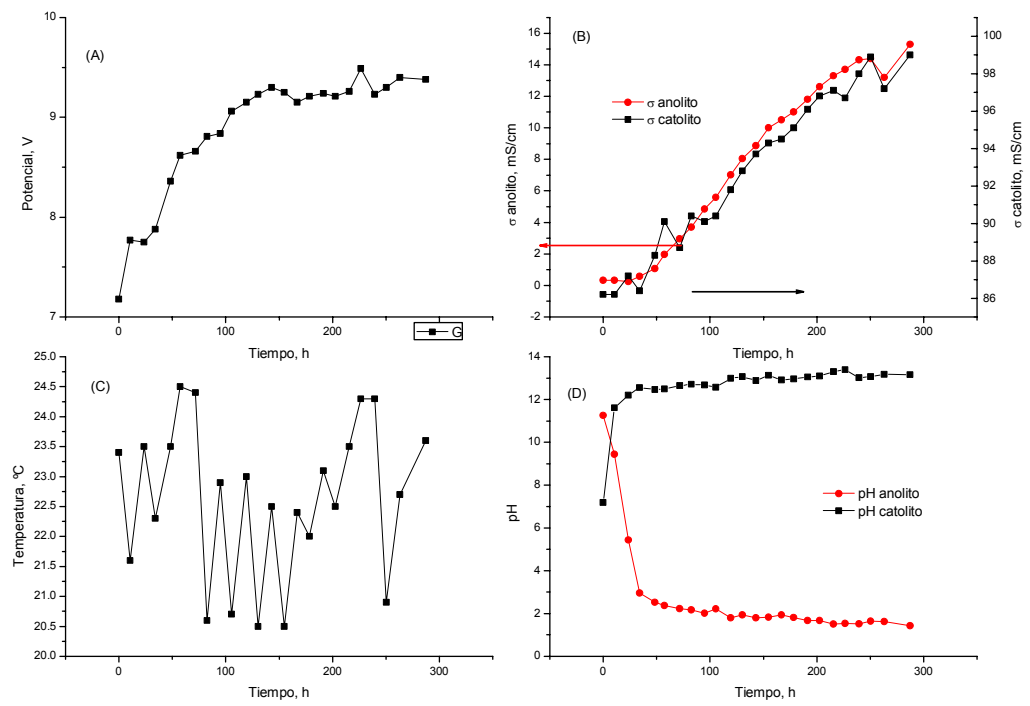

Figure 2: Evolution of the following experimental data during migration test: (A) Effective potential drop, (B) conductivity in anolyte (circle) and catholyte (square) chambers, (C) temperature, and (D) $\mathrm{pH}$ in anolyte (circle) and catholyte (square) chambers.

The values for the non stationary and stationary diffusion coefficients are obtained using equations (1) [6]:

$$
D_{N S}=\frac{2 x^{2}}{\tau v^{2}}\left[v \operatorname{coth} \frac{v}{2}-2\right] ; \quad D_{S}=\frac{J x}{v C_{1} \gamma} ; v=\frac{z F \Delta \phi}{R T}
$$

$\mathrm{x}$ is the sample thickness, $\tau$ is the time lag (time elapsed until the conductivity starts to increase in the anolyte). $\Delta \Phi$ is the mean value of the potential difference between both sides of the sample. $\mathrm{J}$ is the flux of ions in stationary state and is calculated from the slope of the conductivity versus time in the linear region. $\mathrm{C}_{1}$ is the $\mathrm{Cl}^{-}$initial concentration in the catholyte $(1 \mathrm{M}) \cdot \gamma$ is the activity coefficient of the catholyte solution (0.656), and $\mathrm{T}$ is the average temperature recorded during the experiment. The mean values obtained were $D_{N S}=8.36 \cdot 10^{-12} \mathrm{~m}^{2} / \mathrm{s}$ and $\mathrm{D}_{\mathrm{S}}=2.19 \cdot 10^{-12} \mathrm{~m}^{2} / \mathrm{s}$.

\subsection{Mercury intrusion porosimetry results}

MIP measurements have been done on five different samples. One on a specimen not submitted to migration test (reference concrete). The other four samples were obtained after 167 hours (linear zone) and 287 hours (end) of test. For each migration time one sample was taken from the face in contact with the catholyte, and another from the face in contact with the anolyte. It seemed interesting to see 
if there was any variation in microstructure at both sides as previous works showed differences between both sides [17]. The values for the total porosity measured and mercury retained after MIP test are shown in Table 2 . As it can be observed the porosity decreases slightly as the experiment advances, except for the data of the anodic side after 287 hours. The result of a small increase in porosity near the anode has already been reported [17], and associated to the disturbance in the chemical equilibria or a change in the $\mathrm{pH}$, because of the generation of $\mathrm{H}^{+}$at the anode, as can be seen in figure 2(D).

Table 2: Total porosity (\%) of different concrete samples, determined using mercury intrusion porosimetry.

\begin{tabular}{|r|r|r|r|r|}
\hline \multirow{2}{*}{ Time, $\mathrm{h}$} & \multicolumn{2}{|c|}{ Total porosity, \% } & \multicolumn{2}{c|}{ Hg retained, \% } \\
\cline { 2 - 5 } & Anodic side & Cathodic side & Anodic side & Cathodic side \\
\hline 0 & \multicolumn{2}{|c|}{7.99} & \multicolumn{2}{|c|}{55.05} \\
\cline { 2 - 5 } 167 & 7.68 & 7.57 & 62.39 & 54.73 \\
287 & 8.58 & 7.03 & 69.63 & 60.93 \\
\hline
\end{tabular}
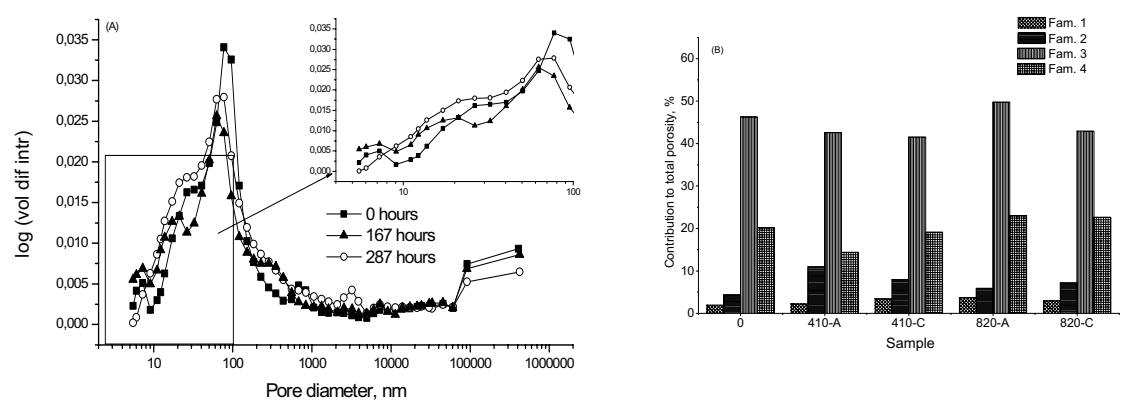

Figure 3: (A) Pore size distributions for: Reference concrete (solid square), 167 hours test / anodic side (solid triangle), and 287 hours test / anodic side (open circle). (B) Contribution to the total porosity of the different pore families determined by MIP.

The most important result is depicted in Figure 3(A), which shows the logarithmic differential of the intrusion volume vs pore size for the reference concrete, and for the samples of the anodic side after 167 and 287 hours. Values of the contributions to total porosity are shown in Figure 3(B). It can be seen in this figure that for the reference concrete five pore families are present in the following diameter ranges: family $1(2000-3000 \mathrm{~nm})$, family $2(700-800 \mathrm{~nm})$, family $3(80-90 \mathrm{~nm})$, family $4(30-40 \mathrm{~nm})$ and family $5(5-10 \mathrm{~nm})$. It is important to notice that the 5 th pore family that appears in the case of concrete not exposed to the experiment and the anodic side after 167 hours becomes so small in the rest of the samples that it is not possible to be detected with the porosimeter used. For families 2 and 3 the central size decreases as the experiment advances. This result also coincides with the prediction of increase of the amount of pores 
of small size [17], possibly due to the reaction and the precipitation of chlorine containing compounds. Family 4 increases its contribution to the total porosity after 287 hours. That means that even when the total porosity does not decrease significantly, most of the pores present become smaller than they were before the experiment. The retention of mercury is also increased, as shown in table 2 . This means that the tortuosity of the pore network increases, especially at the anodic side. This fact coincides with the diminution of pore sizes at almost constant porosity.

\subsection{Impedance spectroscopy results}

Impedance spectra of the concrete specimens subjected to migration were measured every 12 or 24 hours, and the results were successfully fitted to the circuit depicted in Figure 1 using the procedure explained in section 2.2. The analysis of the evolution of the impedance spectra may allow one to understand the modifications of the concrete microstructure caused by migration. Figure 4 shows 3 impedance spectra for 3 different testing times: 10.5, 34.25, and 57.25 hours. It is evident that important changes occur, and that these changes are not only a consequence of the variation in the resistance of the electrolytes. It is interesting to note that the low frequency resistance decreases in the zone when the conductivity increases (as should be expected).

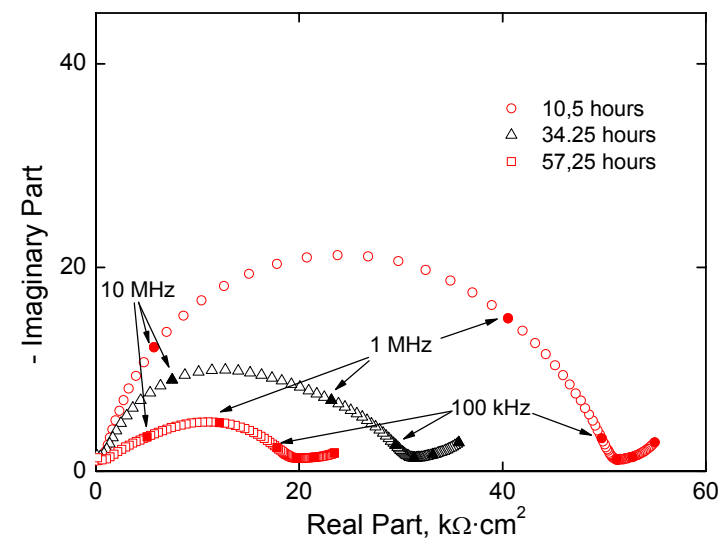

Figure 4: Impedance spectra of the sample after 10.5 (circle), 34.25 (triangle), and 57.25 hours (square) of ionic migration experiment.

The equation used for the fitting of measured spectra is the following:

$Z(\omega)=R_{0}+\frac{Z_{1} Z_{2}}{Z_{1}+Z_{2}} \quad\left(\right.$ where $Z_{1}=\frac{R_{1}}{1+\left(j \omega R_{1} C_{1}\right)^{\alpha_{1}}}$ and $\left.Z_{2}=R_{2}\left(1+\left(j \omega R_{2} C_{2}\right)^{-\alpha_{2}}\right)\right)$

The parameters obtained from the fitting are $\mathrm{R}_{0}, \mathrm{R}_{1}, \mathrm{C}_{1}, \mathrm{R}_{2}, \mathrm{C}_{2}, \alpha_{1}$ and $\alpha_{2}$. The physical meaning of parameters has already been widely discussed $[13,14] . \mathrm{R}_{0}$ corresponds to the electrolytes at both sides of the concrete sample, between the reference electrodes and the sample. Due to the high concentration of $\mathrm{NaCl}$ in the cathodic side, and the fact that conductivity does not decrease on this side during 
the experiment, the variations on $\mathrm{R}_{0}$ will correspond mostly to variations in the conductivity of the anolyte. $\mathrm{R}_{1}$ has been associated to the pores that connect both faces of the concrete sample (percolating pores), while $\mathrm{R}_{2}$ is related to the other pores, the ones that do not connect the two sides of the sample (occluded pores). $\mathrm{C}_{1}$ is a dielectrical capacitance, and is directly related to the solid fraction in the sample, including cement paste and aggregates. $\mathrm{C}_{2}$ is the capacitance associated to the double layer capacitance at the pore walls. $\alpha_{1}$ and $\alpha_{2}$ correspond to ColeCole type time constant dispersion factors. These two factors have values between 0 and 1 . Value 1 corresponds to the absence of dispersion (all the phenomena present have exactly the same time constant), if $\alpha_{\mathrm{i}}<1$ it indicates dispersion (phenomena measured time constants distributed around a central value).
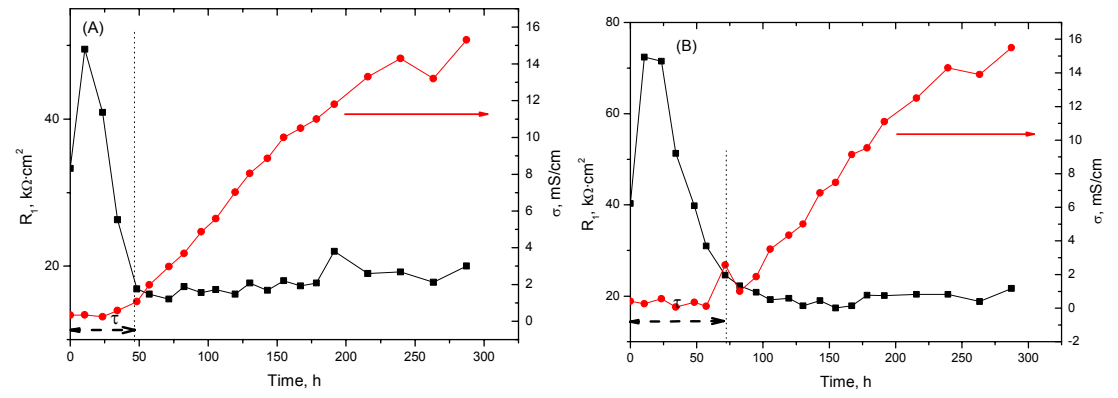

Figure 5: Relation between $R_{1}$ and time-lag for two different samples. See text for details. (A) Sample 1 with $D_{\mathrm{NS}}=8.36 \cdot 10^{-12} \mathrm{~m}^{2} / \mathrm{s}$, $\mathrm{D}_{\mathrm{S}}=2.19 \cdot 10^{-12} \mathrm{~m}^{2} / \mathrm{s}$, and $\tau=42.10 \mathrm{~h}$. (B) Sample 2 with $\mathrm{D}_{\mathrm{NS}}=4.84 \cdot 10^{-12} \mathrm{~m}^{2} / \mathrm{s}, \mathrm{D}_{\mathrm{S}}=2.42 \cdot 10^{-12} \mathrm{~m}^{2} / \mathrm{s}$, and $\tau=73.87 \mathrm{~h}$.

Figure 5(A) shows the evolution of $\mathrm{R}_{1}$ parameter among with anolyte conductivity. During the first 50 hours approximately, figure 5(A) shows no variation for the conductivity of the anolyte and simultaneous steep decreases of $R_{1}$ resistance. The decreasing tendency in resistance $R_{1}$ may be explained as due to the saturation of the concrete sample with $\mathrm{Cl}^{-}$ions. This part of the experiment has been defined before [18] as a transient period during which porosity is filled with diffusing species, and the concentrations in the solid and the liquid come into equilibrium (by absorption). The experimental observations of Figure 5(A) may be considered thus as a further experimental confirmation of the validity of the above mentioned definition. The duration of this transient period, known as time-lag, is used for determining the non-steady state diffusion coefficients [16]. The explained relation between $R_{1}$ and time-lag appears evident comparing figures 5(A) and 5(B). In figure 5(B), $\mathrm{R}_{1}$ and anolyte conductivity are plotted together for another sample with higher time-lag. In both cases (figs. 5(A) and 5(B)) $R_{1}$ value stabilizes when anolyte conductivity starts to increase, i.e. when time-lag is reached. After that initial diminution of the $R_{1}$ value there is a continuous increase until the experiment finishes which is an indication of continuous blocking of percolating paths. The increase observed in $R_{1}$ after approx. 100 hours can be associated to the decreases in total porosity and in the 
mean pore sizes, and to an increase in tortuosity (in accordance with data given in Table 2, and Figure 3). Even though the model used for the fitting of the data is different, some coincidences are observed with the results obtained by Loche et al [10]. The total resistance $R_{1}$ in this work decreases at the initial stage of the experiment, and remains in a value much lower than the initial one, as observed also by Loche et al.

\section{Conclusions}

All the previous results can be summarized in the following conclusions:

1. Modifications are induced in the microstructure of concrete when an electric field is applied to accelerate the movement of ions.

2. Impedance spectroscopy is a useful technique to follow these modifications.

3. The definition of the time-lag period of a chloride migration experiment as the time to sample saturation with chlorides is in good agreement with the IS results obtained in this work.

4. The variations of the dielectric parameters determined trough IS measurements can be interpreted in the following terms: the proportion of pores of small size in concrete increases with the time of exposition to the electric field, the tortuosity of pore network increases, and the porosity decreases slightly. These predictions are confirmed experimentally by MIP results.

\section{Acknowledgements}

This work has been financially supported by the Generalitat Valenciana through project GV05/196, and by the Ministerio de Educación y Ciencia of Spain and Fondo Europeo de Desarrollo Regional (FEDER) through project BIA200605961. Dr I. Sánchez is indebted to the abovementioned Spanish Ministry for a fellowship of the "Juan de la Cierva" programme.

\section{References}

[1] Castellote M., Andrade C., and Alonso C. Measurements of the steady and non-steady-state chloride diffusion coefficients in a migration test by means of monitoring the conductivity in the anolyte chamber. Comparison with natural diffusion tests. Cem. Concr. Res. 31(10), pp. 1411-1420, 2001.

[2] Díaz B., Nóvoa X. R., and Pérez, M. C. Study of the chloride diffusion in mortar: A new method of determining diffusion coefficients based on impedance measurements. Cem. Concr. Comp. 28(3), pp. 237-245, 2006.

[3] Cabeza M., Merino P., Miranda A., Nóvoa X. R., Sánchez I. Impedance spectroscopy study of hardened Portland cement paste. Cem Concr. Res., pp. 881-891, 2002.

[4] D. Whiting, Rapid measurements of the chloride permeability of concrete. Public Roads, 45 (1981) 101-112 
[5] L. Tang, L.O. Nilsson, Rapid determination of the chloride diffusivity in concrete by applying an electric field. ACI Mater. J., 89 (1) (1992) 49-53

[6] M. Castellote, C. Andrade, and C. Alonso, Measurements of the steady and non-steady-state chloride diffusion coefficients in a migration test by means of monitoring the conductivity in the anolyte chamber. Comparison with natural diffusion tests. Cem. Concr. Res. 31, (10), (2001) 1411-1420

[7] M.A. Climent, G. De Vera, J. F. Lopez, E. Viqueira, C. Andrade, A test method for measuring chloride diffusion coefficients through nonsaturated concrete. Part I. the instantaneous plane source diffusion case. Cem. Concr. Res., 32 (2002) 1113-1123

[8] Chlortest Project, www.chlortest.org

[9] M. Siegwart, J.F. Lyness, B.J. McFarland, Change of pore size in concrete due to electrochemical chloride extraction and possible implications for the migration of ions. Cem. Concr. Res. 33 (2003) 1211-1221

[10] J.M. Loche, A. Ammar, P. Dumargue, Influence of the migration of chloride ions on the electrochemical impedance spectroscopy of mortar paste. Cem. Concr. Res., 35, (2005) 1797-1803

[11] ASTM Standard C 1202-97: Standard test method for electrical indication of concrete's ability to resist chloride ion penetration. Annual book of ASTM Standard Section 4 Vol 04.02 (2000)

[12] C. Andrade, L. Soler, X. R Nóvoa, Advances in electrochemical impedance measurements in reinforced concrete. Mater. Sci. Forum, 19214 (1995) 843-856

[13] I. Sanchez, Aplicación de la espectroscopía de impedancia a la determinación de la microestructura y propiedades mecánicas de la pasta y mortero de cemento Pórtland. PhD thesis. Universidade de Vigo (Spain) (2002)

[14] M. Cabeza, P. Merino, A. Miranda, X.R. Nóvoa, I. Sanchez, Impedance spectroscopy study of hardened Portland cement paste. Cem Conr. Res., 32, (2002) 881-891

[15] C. Alonso, C. Andrade, X.R. Nóvoa, M. Keddam, H. Takenouti, Study of the dielectric characteristics of cement paste. Mater. Sci. Forum 289-292 (1998) 15-28

[16] S. Diamond, Mercury porosimetry. An inappropriate method for the measurement of pore size distributions in cement-based materials. Cement and Concrete Research. 30 pp 1517-1525 (2000)

[17] M. Castellote, C. Andrade, C. Alonso, Changes in concrete pore size distribution due to electrochemical chloride migration trials. ACI Mater. J., 96 (3) (1999) 314-319

[18] A. Atkinson, A.K. Nickerson, The diffusion of ions through watersaturated cement, J. Mater. Sci., 19 (1984) 3068-3078

[19] M. Cabeza, M. Keddam, X.R. Nóvoa, I. Sanchez, H, Takenouti, Impedance spectroscopy to characterize the pore structure during the hardening process of Portland cement paste. Electrochim. Acta, 51(2006) 1831-1841 